\title{
Research Article \\ Strong Convergence of an Implicit Algorithm in CAT(0) Spaces
}

\author{
Hafiz Fukhar-ud-din, ${ }^{1}$ Abdul Aziz Domlo, ${ }^{2}$ \\ and Abdul Rahim Khan ${ }^{3}$ \\ ${ }^{1}$ Department of Mathematics, The Islamia University of Bahawalpur, Bahawalpur 63100, Pakistan \\ ${ }^{2}$ Department of Mathematics, Taibah University, Madinah Munawarah 30002, Saudi Arabia \\ ${ }^{3}$ Department of Mathematics and Statistics, King Fahd University of Petroleum and Minerals, \\ Dhahran 31261, Saudi Arabia
}

Correspondence should be addressed to Abdul Rahim Khan, arahim@kfupm.edu.sa

Received 23 November 2010; Accepted 23 December 2010

Academic Editor: Qamrul Hasan Ansari

Copyright (C) 2011 Hafiz Fukhar-ud-din et al. This is an open access article distributed under the Creative Commons Attribution License, which permits unrestricted use, distribution, and reproduction in any medium, provided the original work is properly cited.

We establish strong convergence of an implicit algorithm to a common fixed point of a finite family of generalized asymptotically quasi-nonexpansive maps in CAT(0) spaces. Our work improves and extends several recent results from the current literature.

\section{Introduction}

A metric space $(X, d)$ is said to be a length space if any two points of $X$ are joined by a rectifiable path (i.e., a path of finite length), and the distance between any two points of $X$ is taken to be the infimum of the lengths of all rectifiable paths joining them. In this case, $d$ is said to be a length metric (otherwise known as an inner metric or intrinsic metric). In case no rectifiable path joins two points of the space, the distance between them is taken to be $\infty$.

A geodesic path joining $x \in X$ to $y \in X$ (or, more briefly, a geodesic from $x$ to $y$ ) is a map $c$ from a closed interval $[0, l] \subset \mathbb{R}$ to $X$ such that $c(0)=x, c(l)=y$, and $d\left(c(t), c\left(t^{\prime}\right)\right)=\left|t-t^{\prime}\right|$ for all $t, t^{\prime} \in[0, l]$. In particular, $c$ is an isometry, and $d(x, y)=l$. The image $\alpha$ of $c$ is called a geodesic (or metric) segment joining $x$ and $y$. We say $X$ is (i) a geodesic space if any two points of $X$ are joined by a geodesic and (ii) uniquely geodesic if there is exactly one geodesic joining $x$ and $y$ for each $x, y \in X$, which we will denote by $[x, y]$, called the segment joining $x$ to $y$.

A geodesic triangle $\Delta\left(x_{1}, x_{2}, x_{3}\right)$ in a geodesic metric space $(X, d)$ consists of three points in $X$ (the vertices of $\Delta$ ) and a geodesic segment between each pair of vertices (the edges of $\Delta$ ). A comparison triangle for geodesic triangle $\Delta\left(x_{1}, x_{2}, x_{3}\right)$ in $(X, d)$ is a triangle $\bar{\Delta}\left(x_{1}, x_{2}, x_{3}\right):=$ $\Delta\left(\bar{x}_{1}, \bar{x}_{2}, \bar{x}_{3}\right)$ in $\mathbb{R}^{2}$ such that $d_{\mathbb{R}^{2}}\left(\bar{x}_{i}, \bar{x}_{j}\right)=d\left(x_{i}, x_{j}\right)$ for $i, j \in\{1,2,3\}$. Such a triangle always exists (see [1]). 
A geodesic metric space is said to be a CAT(0) space if all geodesic triangles of appropriate size satisfy the following $\mathrm{CAT}(0)$ comparison axiom.

Let $\Delta$ be a geodesic triangle in $X$, and let $\bar{\Delta} \subset \mathbb{R}^{2}$ be a comparison triangle for $\Delta$. Then $\Delta$ is said to satisfy the CAT(0) inequality if for all $x, y \in \Delta$ and all comparison points $\bar{x}, \bar{y} \in \bar{\Delta}$,

$$
d(x, y) \leq d(\bar{x}, \bar{y}) .
$$

Complete CAT(0) spaces are often called Hadamard spaces (see [2]). If $x, y_{1}, y_{2}$ are points of a CAT(0) space and $y_{0}$ is the midpoint of the segment $\left[y_{1}, y_{2}\right]$, which we will denote by $\left(y_{1} \oplus y_{2}\right) / 2$, then the $\mathrm{CAT}(0)$ inequality implies

$$
d^{2}\left(x, \frac{y_{1} \oplus y_{2}}{2}\right) \leq \frac{1}{2} d^{2}\left(x, y_{1}\right)+\frac{1}{2} d^{2}\left(x, y_{2}\right)-\frac{1}{4} d^{2}\left(y_{1}, y_{2}\right)
$$

The inequality (1.2) is the $(\mathrm{CN})$ inequality of Bruhat and Titz [3]. The above inequality has been extended in [4] as

$$
d^{2}(z, \alpha x \oplus(1-\alpha) y) \leq \alpha d^{2}(z, x)+(1-\alpha) d^{2}(z, y)-\alpha(1-\alpha) d^{2}(x, y)
$$

for any $\alpha \in[0,1]$ and $x, y, z \in X$.

Let us recall that a geodesic metric space is a CAT(0) space if and only if it satisfies the (CN) inequality (see [1, page 163]). Moreover, if $X$ is a CAT(0) metric space and $x, y \in X$, then for any $\alpha \in[0,1]$, there exists a unique point $\alpha x \oplus(1-\alpha) y \in[x, y]$ such that

$$
d(z, \alpha x \oplus(1-\alpha) y) \leq \alpha d(z, x)+(1-\alpha) d(z, y),
$$

for any $z \in X$ and $[x, y]=\{\alpha x \oplus(1-\alpha) y: \alpha \in[0,1]\}$.

A subset $C$ of a CAT(0) space $X$ is convex if for any $x, y \in C$, we have $[x, y] \subset C$.

Let $T$ be a selfmap on a nonempty subset $C$ of $X$. Denote the set of fixed points of $T$ by $F(T)=\{x \in C: T(x)=x\}$. We say $T$ is: (i) asymptotically nonexpansive if there is a sequence $\left\{u_{n}\right\} \subset[0, \infty)$ with $\lim _{n \rightarrow \infty} u_{n}=0$ such that $d\left(T^{n} x, T^{n} y\right) \leq\left(1+u_{n}\right) d(x, y)$ for all $x, y \in C$ and $n \geq 1$, (ii) asymptotically quasi-nonexpansive if $F(T) \neq \phi$ and there is a sequence $\left\{u_{n}\right\} \subset[0, \infty)$ with $\lim _{n \rightarrow \infty} u_{n}=0$ such that $d\left(T^{n} x, p\right) \leq\left(1+u_{n}\right) d(x, p)$ for all $x \in C, p \in F(T)$ and $n \geq 1$, (iii) generalized asymptotically quasi-nonexpansive [5] if $F(T) \neq \emptyset$ and there exist two sequences of real numbers $\left\{u_{n}\right\}$ and $\left\{c_{n}\right\}$ with $\lim _{n \rightarrow \infty} u_{n}=0=\lim _{n \rightarrow \infty} c_{n}$ such that $d\left(T^{n} x, p\right) \leq d(x, p)+\left(1+u_{n}\right) d(x, p)+c_{n}$ for all $x \in C, p \in F(T)$ and $n \geq 1$, (iv) uniformly $L$-Lipschitzian if for some $L>0, d\left(T^{n} x, T^{n} y\right) \leq L d(x, y)$ for all $x, y \in C$ and $n \geq 1$, and (v) semicompact if for any bounded sequence $\left\{x_{n}\right\}$ in $C$ with $d\left(x_{n}, T x_{n}\right) \rightarrow 0$ as $n \rightarrow \infty$, there is a convergent subsequence of $\left\{x_{n}\right\}$.

Denote the indexing set $\{1,2,3, \ldots, N\}$ by $I$. Let $\left\{T_{i}: i \in I\right\}$ be the set of $N$ selfmaps of $C$. Throughout the paper, it is supposed that $F=\bigcap_{i=1}^{N} F\left(T_{i}\right) \neq \phi$. We say condition $(A)$ is satisfied if there exists a nondecreasing function $f:[0, \infty) \rightarrow[0, \infty)$ with $f(0)=0, f(r)>0$ for all $r \in(0, \infty)$ and at least one $T \in\left\{T_{i}: i \in I\right\}$ such that $d(x, T x) \geq f(d(x, F))$ for all $x \in C$ where $d(x, F)=\inf \{d(x, p): p \in F\}$. 
If in definition (iii), $c_{n}=0$ for all $n \geq 1$, then $T$ becomes asymptotically quasinonexpansive, and hence the class of generalized asymptotically quasi-nonexpansive maps includes the class of asymptotically quasi-nonexpansive maps.

Let $\left\{x_{n}\right\}$ be a sequence in a metric space $(X, d)$, and let $C$ be a subset of $X$. We say that $\left\{x_{n}\right\}$ is: (vi) of monotone type(A) with respect to $C$ if for each $p \in C$, there exist two sequences $\left\{r_{n}\right\}$ and $\left\{s_{n}\right\}$ of nonnegative real numbers such that $\sum_{n=1}^{\infty} r_{n}<\infty, \sum_{n=1}^{\infty} s_{n}<\infty$ and $d\left(x_{n+1}, p\right) \leq\left(1+r_{n}\right) d\left(x_{n}, p\right)+s_{n}$, (vii) of monotone type(B) with respect to $C$ if there exist sequences $\left\{r_{n}\right\}$ and $\left\{s_{n}\right\}$ of nonnegative real numbers such that $\sum_{n=1}^{\infty} r_{n}<\infty, \sum_{n=1}^{\infty} s_{n}<\infty$ and $d\left(x_{n+1}, C\right) \leq\left(1+r_{n}\right) d\left(x_{n}, C\right)+s_{n}$ (also see [6]).

From the above definitions, it is clear that sequence of monotone type(A) is a sequence of monotone type(B) but the converse is not true, in general.

Recently, numerous papers have appeared on the iterative approximation of fixed points of asymptotically nonexpansive (asymptotically quasi-nonexpansive) maps through Mann, Ishikawa, and implicit iterates in uniformly convex Banach spaces, convex metric spaces and CAT(0) spaces (see, e.g., [5, 7-16]).

Using the concept of convexity in CAT(0) spaces, a generalization of Sun's implicit algorithm [15] is given by

$$
\begin{aligned}
x_{0} & \in C, \\
x_{1} & =\alpha_{1} x_{0} \oplus\left(1-\alpha_{1}\right) T_{1} x_{1}, \\
x_{2} & =\alpha_{2} x_{1} \oplus\left(1-\alpha_{2}\right) T_{2} x_{2}, \\
& \vdots \\
x_{N} & =\alpha_{N} x_{N-1} \oplus\left(1-\alpha_{N}\right) T_{N} x_{N}, \\
x_{N+1} & =\alpha_{N+1} x_{N} \oplus\left(1-\alpha_{N+1}\right) T_{1}^{2} x_{N+1}, \\
& \vdots \\
x_{2 N} & =\alpha_{2 N} x_{2 N-1} \oplus\left(1-\alpha_{2 N}\right) T_{N}^{2} x_{2 N}, \\
x_{2 N+1} & =\alpha_{2 N+1} x_{2 N} \oplus\left(1-\alpha_{2 N+1}\right) T_{1}^{3} x_{2 N+1},
\end{aligned}
$$

where $0 \leq \alpha_{n} \leq 1$.

Starting from arbitrary $x_{0}$, the above process in the compact form is written as

$$
x_{n}=\alpha_{n} x_{n-1} \oplus\left(1-\alpha_{n}\right) T_{i(n)}^{k(n)} x_{n}, \quad n \geq 1,
$$

where $n=(k-1) N+i, i=i(n) \in I$ and $k=k(n) \geq 1$ is a positive integer such that $k(n) \rightarrow \infty$ as $n \rightarrow \infty$. 
In a normed space, algorithm (1.6) can be written as

$$
x_{0} \in C, \quad x_{n}=\alpha_{n} x_{n-1}+\left(1-\alpha_{n}\right) T_{i(n)}^{k(n)} x_{n}, \quad n \geq 1,
$$

where $n=(k-1) N+i, i=i(n) \in I$ and $k=k(n) \geq 1$ is a positive integer such that $k(n) \rightarrow \infty$ as $n \rightarrow \infty$.

The algorithms (1.6)-(1.7) exist as follows.

Let $X$ be a CAT( 0$)$ space. Then, the following inequality holds:

$$
d(\lambda x \oplus(1-\lambda) z, \lambda y \oplus(1-\lambda) w) \leq \lambda d(x, y)+(1-\lambda) d(z, w)
$$

for all $x, y, z, w \in X$ (see [17]).

Let $\left\{T_{i}: i \in I\right\}$ be the set of $N$ uniformly $L$-Lipschitzian selfmaps of $C$. We show that (1.6) exists. Let $x_{0} \in C$ and $x_{1}=\alpha_{1} x_{0} \oplus\left(1-\alpha_{1}\right) T_{1} x_{1}$. Define $S: C \rightarrow C$ by: $S x=\alpha_{1} x_{0} \oplus\left(1-\alpha_{1}\right) T_{1} x$ for all $x \in C$. The existence of $x_{1}$ is guaranteed if $S$ has a fixed point. For any $x, y \in C$, we have

$$
d(S x, S y) \leq\left(1-\alpha_{1}\right) d\left(T_{1} x, T_{1} y\right) \leq\left(1-\alpha_{1}\right) L\|x-y\| .
$$

Now, $S$ is a contraction if $\left(1-\alpha_{1}\right) L<1$ or $L<1 /\left(1-\alpha_{1}\right)$. As $\alpha_{1} \in(0,1)$, therefore $S$ is a contraction even if $L>1$. By the Banach contraction principle, $S$ has a unique fixed point. Thus, the existence of $x_{1}$ is established. Similarly, we can establish the existence of $x_{2}, x_{3}, x_{4}, \ldots$. Thus, the implicit algorithm (1.6) is well defined. Similarly, we can prove that (1.7) exists.

For implicit iterates, $\mathrm{Xu}$ and Ori [16] proved the following theorem.

Theorem XO (see [16, Theorem 2]). Let $\left\{T_{i}: i \in I\right\}$ be nonexpansive selfmaps on a closed convex subset $C$ of a Hilbert space with $F \neq \phi$, let $x_{0} \in C$, and let $\left\{\alpha_{n}\right\}$ be a sequence in $(0,1)$ such that $\lim _{n \rightarrow \infty} \alpha_{n}=0$. Then, the sequence $x_{n}=\alpha_{n} x_{n-1}+\left(1-\alpha_{n}\right) T x_{n}$, where $n \geq 1$ and $T_{n}=T_{n} \bmod N$, converges weakly to a point in F.

They posed the question: what conditions on the maps $\left\{T_{i}: i \in I\right\}$ and (or) the parameters $\left\{\alpha_{n}\right\}$ are sufficient to guarantee strong convergence of the sequence in Theorem $\mathrm{XO}$ ?

The aim of this paper is to study strong convergence of iterative algorithm (1.6) for the class of uniformly L-Lipschitzian and generalized asymptotically quasi-nonexpansive selfmaps on a CAT(0) space. Thus, we provide a positive answer to Xu and Ori's question for the general class of maps which contains asymptotically quasi-nonexpansive, asymptotically nonexpansive, quasi-nonexpansive, and nonexpansive maps in the setup of CAT(0) spaces. It is worth mentioning that if an implicit iteration algorithm without an error term converges, then the method of proof generally carries over easily to algorithm with bounded error terms. Thus, our results also hold if we add bounded error terms to the implicit iteration scheme considered. Our results constitute generalizations of several important known results.

We need the following useful lemma for the development of our convergence results. 
Fixed Point Theory and Applications

Lemma 1.1 (see [14, Lemma 1.1]). Let $\left\{r_{n}\right\}$ and $\left\{s_{n}\right\}$ be two nonnegative sequences of real numbers, satisfying the following condition:

$$
r_{n+1} \leq\left(1+s_{n}\right) r_{n} \quad \forall n \geq n_{0} \text { for some } n_{0} \geq 1
$$

If $\sum_{n=1}^{\infty} s_{n}<\infty$, then $\lim _{n \rightarrow \infty} r_{n}$ exists.

\section{Convergence in CAT(0) Spaces}

We establish some convergence results for the algorithm (1.6) to a common fixed point of a finite family of uniformly $L$-Lipschitzian and generalized asymptotically quasi-nonexpansive selfmaps in the general class of CAT(0) spaces. The following result extends Theorem XO; our methods of proofs are based on the ideas developed in [15].

Theorem 2.1. Let $(X, d)$ be a complete $C A T(0)$ space, and let $C$ be a nonempty closed convex subset of $X$. Let $\left\{T_{i}: i \in I\right\}$ be $N$ uniformly L-Lipschitzian and generalized asymptotically quasi-nonexpansive selfmaps of $C$ with $\left\{u_{i n}\right\},\left\{c_{i n}\right\} \subset[0, \infty)$ such that $\sum_{n=1}^{\infty} u_{i n}<\infty$ and $\sum_{n=1}^{\infty} c_{i n}<\infty$ for all $i \in I$. Suppose that $F$ is closed. Starting from arbitrary $x_{0} \in C$, define the sequence $\left\{x_{n}\right\}$ by the algorithm (1.6), where $\left\{\alpha_{n}\right\} \subset[\delta, 1-\delta]$ for some $\delta \in(0,1 / 2)$. Then, $\left\{x_{n}\right\}$ is of monotone type $(A)$ and monotone type $(B)$ with respect to $F$. Moreover, $\left\{x_{n}\right\}$ converges strongly to a common fixed point of the maps $\left\{T_{i}: i \in I\right\}$ if and only if $\liminf _{n \rightarrow \infty} d\left(x_{n}, F\right)=0$.

Proof. First, we show that $\left\{x_{n}\right\}$ is of monotone type $(A)$ and monotone type( $\left.B\right)$ with respect to $F$. Let $p \in F$. Then, from (1.6), we obtain that

$$
\begin{aligned}
d\left(x_{n}, p\right) & =d\left(\alpha_{n} x_{n-1} \oplus\left(1-\alpha_{n}\right) T_{i(n)}^{k(n)} x_{n}, p\right) \\
& \leq \alpha_{n} d\left(x_{n-1}, p\right)+\left(1-\alpha_{n}\right) d\left(T_{i(n)}^{k(n)} x_{n}, p\right) \\
& \leq \alpha_{n} d\left(x_{n-1}, p\right)+\left(1-\alpha_{n}\right)\left[d\left(x_{n}, p\right)+u_{i k(n)} d\left(x_{n}, p\right)+c_{i k(n)}\right] \\
& \leq \alpha_{n} d\left(x_{n-1}, p\right)+\left(1-\alpha_{n}+u_{i k(n)}\right) d\left(x_{n}, p\right)+\left(1-\alpha_{n}\right) c_{i k(n)} .
\end{aligned}
$$

Since $\alpha_{n} \in[\delta, 1-\delta]$, the above inequlaity gives that

$$
d\left(x_{n}, p\right) \leq d\left(x_{n-1}, p\right)+\frac{u_{i k(n)}}{\delta} d\left(x_{n}, p\right)+\left(\frac{1}{\delta}-1\right) c_{i k(n)}
$$

On simplification, we have that

$$
d\left(x_{n}, p\right) \leq \frac{\delta}{\delta-u_{i k(n)}} d\left(x_{n-1}, p\right)+\left(\frac{1}{\delta}-1\right) \frac{\delta}{\delta-u_{i k(n)}} c_{i k(n)} .
$$

Let $1+v_{i k(n)}=\delta /\left(\delta-u_{i k(n)}\right)=1+u_{i k(n)} /\left(\delta-u_{i k(n)}\right)$ and $\gamma_{i k(n)}=(1 / \delta-1)\left(1+v_{i k(n)}\right) c_{i k(n)}$. Since $\sum_{k(n)=1}^{\infty} u_{i k(n)}<\infty$ for all $i \in I$, therefore $\lim _{k(n) \rightarrow \infty} u_{i k(n)}=0$, and hence, there exists a 
natural number $n_{1}$ such that $u_{i k(n)}<\delta / 2$ for $k(n) \geq n_{1} / N+1$ or $n>n_{1}$. Then, we have that $\sum_{k(n)=1}^{\infty} v_{i k(n)}<(2 / \delta) \sum_{k(n)=1}^{\infty} u_{i k(n)}<\infty$. Similarly, $\sum_{k(n)=1}^{\infty} \gamma_{i k(n)}<\infty$.

Now, from (2.3), for $k(n) \geq n_{1} / N+1$, we get that

$$
\begin{aligned}
& d\left(x_{n}, p\right) \leq\left(1+v_{i k(n)}\right) d\left(x_{n-1}, p\right)+\gamma_{i k(n)}, \\
& d\left(x_{n}, F\right) \leq\left(1+v_{i k(n)}\right) d\left(x_{n-1}, F\right)+\gamma_{i k(n)} .
\end{aligned}
$$

These inequalities, respectively, prove that $\left\{x_{n}\right\}$ is a sequence of monotone type(A) and monotone type(B) with respect to $F$.

Next, we prove that $\left\{x_{n}\right\}$ converges strongly to a common fixed point of the maps $\left\{T_{i}: i \in I\right\}$ if and only if $\liminf _{n \rightarrow \infty} d\left(x_{n}, F\right)=0$.

If $x_{n} \rightarrow p \in F$, then $\lim _{n \rightarrow \infty} d\left(x_{n}, p\right)=0$. Since $0 \leq d\left(x_{n}, F\right) \leq d\left(x_{n}, p\right)$, we have $\liminf _{n \rightarrow \infty} d\left(x_{n}, F\right)=0$.

Conversely, suppose that $\liminf _{n \rightarrow \infty} d\left(x_{n}, F\right)=0$. Applying Lemma 1.1 to (2.5), we have that $\lim _{n \rightarrow \infty} d\left(x_{n}, F\right)$ exists. Further, by assumption $\operatorname{lim~inf}_{n \rightarrow \infty} d\left(x_{n}, F\right)=0$, we conclude that $\lim _{n \rightarrow \infty} d\left(x_{n}, F\right)=0$. Next, we show that $\left\{x_{n}\right\}$ is a Cauchy sequence.

Since $x \leq \exp (x-1)$ for $x \geq 1$, therefore from (2.4), we have

$$
\begin{aligned}
d\left(x_{n+m}, p\right) & \leq \exp \left(\sum_{i=1}^{N} \sum_{k(n)=1}^{\infty} v_{i k(n)}\right) d\left(x_{n}, p\right)+\sum_{i=1}^{N} \sum_{k(n)=1}^{\infty} \gamma_{i k(n)} \\
& <M d\left(x_{n}, p\right)+\sum_{i=1}^{N} \sum_{k(n)=1}^{\infty} \gamma_{i k(n),}
\end{aligned}
$$

for the natural numbers $m, n$, where $M=\exp \left\{\sum_{i=1}^{N} \sum_{k(n)=1}^{\infty} v_{i k(n)}\right\}+1<\infty$. Since $\lim _{n \rightarrow \infty} d\left(x_{n}, F\right)=0$, therefore for any $\epsilon>0$, there exists a natural number $n_{0}$ such that $d\left(x_{n}, F\right)<\epsilon / 4 M$ and $\sum_{i=1}^{N} \sum_{j=n}^{\infty} \gamma_{i j} \leq \epsilon / 4$ for all $n \geq n_{0}$. So, we can find $p^{*} \in F$ such that $d\left(x_{n_{0}}, p^{*}\right) \leq \epsilon / 4 M$. Hence, for all $n \geq n_{0}$ and $m \geq 1$, we have that

$$
\begin{aligned}
d\left(x_{n+m}, x_{n}\right) & \leq d\left(x_{n+m}, p^{*}\right)+d\left(x_{n}, p^{*}\right) \\
& <M d\left(x_{n_{0}}, p^{*}\right)+\sum_{i=1}^{N} \sum_{j=n_{0}}^{\infty} \gamma_{i j}+M d\left(x_{n_{0}}, p^{*}\right)+\sum_{i=1}^{N} \sum_{j=n_{0}}^{\infty} \gamma_{i j} \\
& =2\left(M d\left(x_{n_{0}}, p^{*}\right)+\sum_{i=1}^{N} \sum_{j=n_{0}}^{\infty} \gamma_{i j}+M d\left(x_{n_{0}}, p^{*}\right)\right) \leq 2\left(\frac{M \epsilon}{4 M}+\frac{\epsilon}{4}\right)=\epsilon
\end{aligned}
$$

This proves that $\left\{x_{n}\right\}$ is a Cauchy sequence. Let $\lim _{n \rightarrow \infty} x_{n}=z$. Since $C$ is closed, therefore $z \in C$. Next, we show that $z \in F$. Now, the following two inequalities:

$$
\begin{array}{ll}
d(z, p) \leq d\left(z, x_{n}\right)+d\left(x_{n}, p\right) & \forall p \in F, n \geq 1, \\
d\left(z, x_{n}\right) \leq d(z, p)+d\left(x_{n}, p\right) & \forall p \in F, n \geq 1
\end{array}
$$


give that

$$
-d\left(z, x_{n}\right) \leq d(z, F)-d\left(x_{n}, F\right) \leq d\left(z, x_{n}\right), \quad n \geq 1
$$

That is,

$$
\left|d(z, F)-d\left(x_{n}, F\right)\right| \leq d\left(z, x_{n}\right), \quad n \geq 1 .
$$

As $\lim _{n \rightarrow \infty} x_{n}=z$ and $\lim _{n \rightarrow \infty} d\left(x_{n}, F\right)=0$, we conclude that $z \in F$.

We deduce some results from Theorem 2.1 as follows.

Corollary 2.2. Let $(X, d)$ be a complete $C A T(0)$ space, and let $C$ be a nonempty closed convex subset of $X$. Let $\left\{T_{i}: i \in I\right\}$ be $N$ uniformly L-Lipschitzian and generalized asymptotically quasinonexpansive selfmaps of $C$ with $\left\{u_{i n}\right\},\left\{c_{i n}\right\} \subset[0, \infty)$ such that $\sum_{n=1}^{\infty} u_{i n}<\infty$ and $\sum_{n=1}^{\infty} c_{i n}<\infty$ for all $i \in I$. Suppose that $F$ is closed. Starting from arbitaray $x_{0} \in C$, define the sequence $\left\{x_{n}\right\}$ by the algorithm (1.6), where $\left\{\alpha_{n}\right\} \subset[\delta, 1-\delta]$ for some $\delta \in(0,1 / 2)$. Then, $\left\{x_{n}\right\}$ converges strongly to a common fixed point of the maps $\left\{T_{i}: i \in I\right\}$ if and only if there exists some subsequence $\left\{x_{n_{j}}\right\}$ of $\left\{x_{n}\right\}$ which converges to $p \in F$.

Corollary 2.3. Let $(X, d)$ be a complete $C A T(0)$ space, and let $C$ be a nonempty closed convex subset of X. Let $\left\{T_{i}: i \in I\right\}$ be $N$ uniformly L-Lipschitzian and asymptotically quasi-nonexpansive selfmaps of $C$ with $\left\{u_{i n}\right\} \subset[0, \infty)$ such that $\sum_{n=1}^{\infty} u_{i n}<\infty$ for all $i \in I$. Starting from arbitaray $x_{0} \in C$, define the sequence $\left\{x_{n}\right\}$ by the algorithm (1.6), where $\left\{\alpha_{n}\right\} \subset[\delta, 1-\delta]$ for some $\delta \in(0,1 / 2)$. Then, $\left\{x_{n}\right\}$ is of monotone type $(A)$ and monotone type $(B)$ with respect to $F$. Moreover, $\left\{x_{n}\right\}$ converges strongly to a common fixed point of the maps $\left\{T_{i}: i \in I\right\}$ if and only if $\operatorname{lim~inf}_{n \rightarrow \infty} d\left(x_{n}, F\right)=0$.

Proof. Follows from Theorem 2.1 with $c_{i n}=0$ for all $n \geq 1$.

Corollary 2.4. Let $X$ be a Banach space, and let $C$ be a nonempty closed convex subset of $X$. Let $\left\{T_{i}: i \in I\right\}$ be $N$ asymptotically quasi-nonexpansive self-maps of $C$ with $\left\{u_{i n}\right\} \subset[0, \infty)$ such that $\sum_{n=1}^{\infty} u_{\text {in }}<\infty$ for all $i \in I$. Starting from arbitaray $x_{0} \in C$, define the sequence $\left\{x_{n}\right\}$ by the algorithm (1.7), where $\left\{\alpha_{n}\right\} \subset[\delta, 1-\delta]$ for some $\delta \in(0,1 / 2)$. Then, $\left\{x_{n}\right\}$ is of monotone type $(A)$ and monotone type $(B)$ with respect to $F$. Moreover, $\left\{x_{n}\right\}$ converges strongly to a common fixed point of the maps $\left\{T_{i}: i \in I\right\}$ if and only if $\liminf _{n \rightarrow \infty} d\left(x_{n}, F\right)=0$.

Proof. Take $\lambda x \oplus(1-\lambda) y=\lambda x+(1-\lambda) y$ in Corollary 2.3.

The lemma to follow establishes an approximate sequence, and as a consequence of that, we find another strong convergence theorem for (1.6).

Lemma 2.5. Let $(X, d)$ be a complete $C A T(0)$ space, and let $C$ be a nonempty closed convex subset of $X$. Let $\left\{T_{i}: i \in I\right\}$ be $N$ uniformly L-Lipschitzian and generalized asymptotically quasi-nonexpansive selfmaps of $C$ with $\left\{u_{i n}\right\},\left\{c_{i n}\right\} \subset[0, \infty)$ such that $\sum_{n=1}^{\infty} u_{i n}<\infty$ and $\sum_{n=1}^{\infty} c_{i n}<\infty$ for all $i \in I$. Suppose that $F$ is closed. Let $\left\{\alpha_{n}\right\} \subset[\delta, 1-\delta]$ for some $\delta \in(0,1 / 2)$. From arbitaray $x_{0} \in C$, define the sequence $\left\{x_{n}\right\}$ by (1.6). Then, $\lim _{n \rightarrow \infty} d\left(x_{n}, T_{l} x_{n}\right)=0$ for all $i \in I$. 
Proof. Note that $\left\{x_{n}\right\}$ is bounded as $\lim _{n \rightarrow \infty} d\left(x_{n}, p\right)$ exists (proved in Theorem 2.1). So, there exists $R>0$ and $x_{0} \in X$ such that $x_{n} \in B_{R}\left(x_{0}\right)=\left\{x: d\left(x, x_{0}\right)<R\right\}$ for all $n \geq 1$. Denote $d\left(x_{n-1}, T_{i(n)}^{k(n)} x_{n}\right)$ by $\sigma_{n}$.

We claim that $\lim _{n \rightarrow \infty} \sigma_{n}=0$.

For any $p \in F$, apply (1.3) to (1.6) and get

$$
\begin{aligned}
d^{2}\left(x_{n}, p\right)= & d^{2}\left(\alpha_{n} x_{n-1} \oplus\left(1-\alpha_{n}\right) T_{i(n)}^{k(n)} x_{n}, p\right) \\
\leq & \alpha_{n} d^{2}\left(x_{n-1}, p\right)+\left(1-\alpha_{n}\right)\left[\left(1+u_{i k(n)}\right) d\left(x_{n}, p\right)+c_{i k(n)}\right]^{2} \\
& -\alpha_{n}\left(1-\alpha_{n}\right) d^{2}\left(T_{i(n)}^{k(n)} x_{n}, x_{n-1}\right)
\end{aligned}
$$

further, using (2.4), we obtain

$$
\begin{aligned}
2 \delta^{3} \sigma_{n}^{2} \leq & \alpha_{n} d^{2}\left(x_{n-1}, x^{*}\right)-d^{2}\left(x_{n}, x^{*}\right) \\
& +\left(1-\alpha_{n}\right)\left[\left(1+u_{i k(n)}\right)\left(1+v_{i k(n)}\right) d\left(x_{n-1}, x^{*}\right)+\left(1+u_{i k(n)}\right) \gamma_{i k(n)}+c_{i k(n)}\right]^{2}
\end{aligned}
$$

which implies that

$$
\begin{aligned}
2 \delta^{3} \sigma_{n}^{2} \leq & \alpha_{n} d^{2}\left(x_{n-1}, p\right)+\left(1-\alpha_{n}\right) d^{2}\left(x_{n-1}, p\right) \\
& +\left(u_{i k(n)}+v_{i k(n)}+\gamma_{i k(n)}+c_{i k(n)}\right) M-d^{2}\left(x_{n}, p\right)
\end{aligned}
$$

for some consant $M>0$. This gives that

$$
2 \delta^{3} \sigma_{n}^{2} \leq d^{2}\left(x_{n-1}, p\right)-d^{2}\left(x_{n}, p\right)+\sigma_{i k(n)} M
$$

where $\sigma_{i k(n)}=u_{i k(n)}+v_{i k(n)}+\gamma_{i k(n)}+c_{i k(n)}$.

For $m \geq 1$, we have that

$$
\begin{aligned}
2 \delta^{3} \sum_{n=1}^{m} \sigma_{n}^{2} & \leq d^{2}\left(x_{0}, p\right)-d^{2}\left(x_{m}, p\right)+\sum_{k(n)=1}^{m} \sigma_{i k(n)} M \\
& \leq d^{2}\left(x_{0}, p\right)+\sum_{k(n)=1}^{m} \sigma_{i k(n)} M .
\end{aligned}
$$

When $m \rightarrow \infty$, we have that $\sum_{n=1}^{\infty} \sigma_{n}^{2}<\infty$ as $\sum_{k(n)=1}^{\infty} \sigma_{i k(n)}<\infty$.

Hence,

$$
\lim _{n \rightarrow \infty} \sigma_{n}=0
$$


Further,

$$
\begin{aligned}
d\left(x_{n}, x_{n-1}\right) & \leq\left(1-\alpha_{n}\right) d\left(T_{i(n)}^{k(n)} x_{n}, x_{n-1}\right) \\
& =\left(1-\alpha_{n}\right) \sigma_{n} \leq(1-\delta) \sigma_{n}
\end{aligned}
$$

implies that $\lim _{n \rightarrow \infty} d\left(x_{n}, x_{n-1}\right)=0$.

For a fixed $j \in I$, we have $d\left(x_{n+j}, x_{n}\right) \leq d\left(x_{n+j}, x_{n+j-1}\right)+\cdots+d\left(x_{n}, x_{n-1}\right)$, and hence

$$
\lim _{n \rightarrow \infty} d\left(x_{n+j}, x_{n}\right)=0 \quad \forall j \in I
$$

For $n>N, n=(n-N)(\bmod N)$. Also, $n=(k(n)-1) N+i(n)$. Hence, $n-N=((k(n)-1)-$ 1) $N+i(n)=(k(n-N) N+i(n-N)$.

That is, $k(n-N)=k(n)-1$ and $i(n-N)=i(n)$.

Therefore, we have

$$
\begin{aligned}
d\left(x_{n-1}, T_{n} x_{n}\right) & \leq d\left(x_{n-1}, T_{i(n)}^{k(n)} x_{n}\right)+d\left(T_{i(n)}^{k(n)} x_{n}, T x_{n}\right) \\
& \leq \sigma_{n}+L d\left(T_{i(n)}^{k(n)-1} x_{n}, x_{n}\right) \\
& \leq \sigma_{n}+L^{2} d\left(x_{n}, x_{n-N}\right)+L d\left(T_{i(n-N)}^{k(n-N)} x_{n-N}, x_{(n-N)-1}\right)+L d\left(x_{(n-N)-1}, x_{n}\right) \\
& =\sigma_{n}+L^{2} d\left(x_{n}, x_{n-N}\right)+L \sigma_{n-N}+L d\left(x_{(n-N)-1}, x_{n}\right),
\end{aligned}
$$

which together with (2.16) and (2.18) yields that $\lim _{n \rightarrow \infty} d\left(x_{n-1}, T x_{n}\right)=0$.

Since

$$
d\left(x_{n}, T x_{n}\right) \leq d\left(x_{n}, x_{n-1}\right)+d\left(x_{n-1}, T_{n} x_{n}\right),
$$

we have

$$
\lim _{n \rightarrow \infty} d\left(x_{n}, T_{n} x_{n}\right)=0
$$

Hence, for all $l \in I$,

$$
\begin{aligned}
d\left(x_{n}, T_{n+l} x_{n}\right) & \leq d\left(x_{n}, x_{n+l}\right)+d\left(x_{n+l}, T_{n+l} x_{n+l}\right)+d\left(T_{n+l} x_{n+l}, T_{n+l} x_{n}\right) \\
& \leq(1+L) d\left(x_{n}, x_{n+l}\right)+d\left(x_{n+l}, T_{n+l} x_{n+l}\right),
\end{aligned}
$$

together with (2.18) and (2.21) implies that

$$
\lim _{n \rightarrow \infty} d\left(x_{n}, T_{n+l} x_{n}\right)=0 \quad \forall l \in I .
$$

Thus, $\lim _{n \rightarrow \infty} d\left(x_{n}, T_{l} x_{n}\right)=0$ for all $l \in I$. 
Theorem 2.6. Let $(X, d)$ be a complete $C A T(0)$ space, and let $C$ be a nonempty closed convex subset of $X$. Let $\left\{T_{i}: i \in I\right\}$ be $N$-uniformly L-Lipschitzian and generalized asymptotically quasi-nonexpansive selfmaps of $C$ with $\left\{u_{i n}\right\},\left\{c_{i n}\right\} \subset[0, \infty)$ such that $\sum_{n=1}^{\infty} u_{i n}<\infty$ and $\sum_{n=1}^{\infty} c_{i n}<\infty$ for all $i \in I$. Suppose that $F$ is closed, and there exists one member $T$ in $\left\{T_{i}: i \in I\right\}$ which is either semicompact or satisfies condition $(A)$. Let $\left\{\alpha_{n}\right\} \subset[\delta, 1-\delta]$ for some $\delta \in(0,1 / 2)$. From arbitaray $x_{0} \in C$, define the sequence $\left\{x_{n}\right\}$ by algorithm (1.6). Then, $\left\{x_{n}\right\}$ converges strongly to a common fixed point of the maps in $\left\{T_{i}: i \in I\right\}$.

Proof. Without loss of generality, we may assume that $T_{1}$ is either semicompact or satisfies condition $(A)$. If $T_{1}$ is semicompact, then there exists a subsequence $\left\{x_{n_{\mathrm{j}}}\right\}$ of $\left\{x_{n}\right\}$ such that $x_{n_{j}} \rightarrow x^{*} \in C$ as $j \rightarrow \infty$. Now, Lemma 2.5 guarantees that $\lim _{n \rightarrow \infty} d\left(x_{n_{j}}, T_{l} x_{n_{j}}\right)=0$ for all $l \in I$ and so $d\left(x^{*}, T_{l} x^{*}\right)=0$ for all $l \in I$. This implies that $x^{*} \in F$. Therefore, $\lim _{\text {inf }} \rightarrow \infty d\left(x_{n}, F\right)=0$. If $T_{1}$ satisfies condition $(A)$, then we also have $\liminf _{n \rightarrow \infty} d\left(x_{n}, F\right)=0$. Now, Theorem 2.1 gaurantees that $\left\{x_{n}\right\}$ converges strongly to a point in $F$.

Finally, we state two corollaries to the above theorem.

Corollary 2.7. Let $(X, d)$ be a complete $C A T(0)$ space and let $C$ be a nonempty closed convex subset of $X$. Let $\left\{T_{i}: i \in I\right\}$ be $N$ uniformly L-Lipschizian and asymptotically quasi-nonexpansive selfmaps of $C$ with $\left\{u_{i n}\right\} \subset[0, \infty)$ such that $\sum_{n=1}^{\infty} u_{i n}<\infty$ for all $i \in I$. Suppose that there exists one member $T$ in $\left\{T_{i}: i \in I\right\}$ which is either semicompact or satisfies condition $(A)$. From arbitaray $x_{0} \in C$, define the sequence $\left\{x_{n}\right\}$ by algorithm (1.6), where $\left\{\alpha_{n}\right\} \subset[\delta, 1-\delta]$ for some $\delta \in(0,1 / 2)$. Then, $\left\{x_{n}\right\}$ converges strongly to a common fixed point of the maps in $\left\{T_{i}: i \in I\right\}$.

Corollary 2.8. Let $(X, d)$ be a complete $C A T(0)$ space, and let $C$ be a nonempty closed convex subset of $X$. Let $\left\{T_{i}: i \in I\right\}$ be $N$ asymptotically nonexpansive selfmaps of $C$ with $\left\{u_{i n}\right\} \subset[0, \infty)$ such that $\sum_{n=1}^{\infty} u_{i n}<\infty$ for all $i \in I$. Suppose that there exists one member $T$ in $\left\{T_{i}: i \in I\right\}$ which is either semicompact or satisfies condition $(A)$. From arbitrary $x_{0} \in C$, define the sequence $\left\{x_{n}\right\}$ by algorithm (1.6), where $\left\{\alpha_{n}\right\} \subset[\delta, 1-\delta]$ for some $\delta \in(0,1)$. Then, $\left\{x_{n}\right\}$ converges strongly to a common fixed point of the maps in $\left\{T_{i}: i \in I\right\}$.

Remark 2.9. The corresponding approximation results for a finite family of asymptotically quasi-nonexpansive maps on: (i) uniformly convex Banach spaces [5, 14, 15], (ii) convex metric spaces [13], (iii) CAT(0) spaces [12] are immediate consequences of our results.

Remark 2.10. Various algorithms and their strong convergence play an important role in finding a common element of the set of fixed (common fixed) point for different classes of mapping(s) and the set of solutions of an equilibrium problem in the framework of Hilbert spaces and Banach spaces; for details we refer to [18-20].

\section{Acknowledgments}

The author A. R. Khan gratefully acknowledges King Fahd University of Petroleum and Minerals and SABIC for supporting research project no. SB100012.

\section{References}

[1] M. R. Bridson and A. Haefliger, Metric Spaces of Non-Positive Curvature, vol. 319 of Grundlehren der Mathematischen Wissenschaften, Springer, Berlin, Germany, 1999. 
[2] M. A. Khamsi and W. A. Kirk, An Introduction to Metric Spaces and Fixed Point Theory, Pure and Applied Mathematics, Wiley-Interscience, New York, NY, USA, 2001.

[3] F. Bruhat and J. Tits, "Groupes réductifs sur un corps local," Institut des Hautes Études Scientifiques. Publications Mathématiques, no. 41, pp. 5-251, 1972.

[4] S. Dhompongsa and B. Panyanak, "On $\Delta$-convergence theorems in CAT(0) spaces," Computers $\mathcal{E}$ Mathematics with Applications, vol. 56, no. 10, pp. 2572-2579, 2008.

[5] S. Imnang and S. Suantai, "Common fixed points of multistep Noor iterations with errors for a finite family of generalized asymptotically quasi-nonexpansive mappings," Abstract and Applied Analysis, vol. 2009, Article ID 728510, 14 pages, 2009.

[6] H. Y. Zhou, G. L. Gao, G. T. Guo, and Y. J. Cho, "Some general convergence principles with applications," Bulletin of the Korean Mathematical Society, vol. 40, no. 3, pp. 351-363, 2003.

[7] H. Fukhar-ud-din and A. R. Khan, "Approximating common fixed points of asymptotically nonexpansive maps in uniformly convex Banach spaces," Computers E Mathematics with Applications, vol. 53, no. 9, pp. 1349-1360, 2007.

[8] H. Fukhar-ud-din and A. R. Khan, "Convergence of implicit iterates with errors for mappings with unbounded domain in Banach spaces," International Journal of Mathematics and Mathematical Sciences, no. 10 , pp. 1643-1653, 2005.

[9] H. Fukhar-ud-din, A. R. Khan, D. O’Regan, and R. P. Agarwal, “An implicit iteration scheme with errors for a finite family of uniformly continuous mappings," Functional Differential Equations, vol. 14, no. 2-4, pp. 245-256, 2007.

[10] H. Fukhar-ud-din and S. H. Khan, "Convergence of iterates with errors of asymptotically quasinonexpansive mappings and applications," Journal of Mathematical Analysis and Applications, vol. 328, no. 2, pp. 821-829, 2007.

[11] W. Guo and Y. J. Cho, "On the strong convergence of the implicit iterative processes with errors for a finite family of asymptotically nonexpansive mappings," Applied Mathematics Letters, vol. 21, no. 10, pp. 1046-1052, 2008.

[12] A. R. Khan, M. A. Khamsi, and H. Fukhar-ud-din, "Strong convergence of a general iteration scheme in CAT(0) spaces," Nonlinear Analysis: Theory, Methods and Applications, vol. 74, no. 3, pp. 783-791, 2011.

[13] A. R. Khan and M. A. Ahmed, "Convergence of a general iterative scheme for a finite family of asymptotically quasi-nonexpansive mappings in convex metric spaces and applications," Computers $\mathcal{E}$ Mathematics with Applications, vol. 59, no. 8, pp. 2990-2995, 2010.

[14] A. R. Khan, A.-A. Domlo, and H. Fukhar-ud-din, "Common fixed points Noor iteration for a finite family of asymptotically quasi-nonexpansive mappings in Banach spaces," Journal of Mathematical Analysis and Applications, vol. 341, no. 1, pp. 1-11, 2008.

[15] Z. Sun, "Strong convergence of an implicit iteration process for a finite family of asymptotically quasinonexpansive mappings," Journal of Mathematical Analysis and Applications, vol. 286, no. 1, pp. 351-358, 2003.

[16] H.-K. Xu and R. G. Ori, "An implicit iteration process for nonexpansive mappings," Numerical Functional Analysis and Optimization, vol. 22, no. 5-6, pp. 767-773, 2001.

[17] L. Leustean, "A quadratic rate of asymptotic regularity for CAT(0)-spaces," Journal of Mathematical Analysis and Applications, vol. 325, no. 1, pp. 386-399, 2007.

[18] A. Tada and W. Takahashi, "Weak and strong convergence theorems for a nonexpansive mapping and an equilibrium problem," Journal of Optimization Theory and Applications, vol. 133, pp. 359-370, 2007.

[19] L.-C. Ceng, S. Al-Homidan, Q. H. Ansari, and J.-C. Yao, “An iterative scheme for equilibrium problems and fixed point problems of strict pseudo-contraction mappings," Journal of Computational and Applied Mathematics, vol. 223, pp. 967-974, 2009.

[20] X. Qin, Y. J. Cho, and S. M. Kang, "Convergence theorems of common elements for equilibrium problems and fixed point problems in Banach spaces," Journal of Computational and Applied Mathematics, vol. 225, pp. 20-30, 2009. 